\title{
EDUCAÇÃO E ESPORTE: ANALISANDO O TEMPO ESCOLAR DO ESTUDANTE-ATLETA DE FUTEBOL ${ }^{1}$
}

\author{
HUGO PAULA ALMEIDA DA ROCHA ${ }^{2}$ \\ ORCID: https://orcid.org/0000-0003-2237-1155 \\ LEONARDO BERNARDES SILVA DE MELO ${ }^{3}$ \\ ORCID: https://orcid.org/0000-0003-4527-6556 \\ MIGUEL ATAÍDE PINTO DA COSTA ${ }^{4}$ \\ ORCID: https://orcid.org/0000-0002-6498-3435 \\ ANTONIO JORGE GONÇALVES SOARES ${ }^{5}$ \\ ORCID: https://orcid.org/0000-0001-7769-9268
}

\begin{abstract}
RESUMO: $\mathrm{O}$ artigo analisa o Tempo de Permanência na Escola (TPE) dos estudantes-atletas de futebol a partir da adaptação do modelo de cálculo proposto por Neri (2009). A variável tempo nos serviu para verificar o investimento do estudante-atleta na dupla carreira esportiva. Realizamos a pesquisa com 62 estudantes-atletas residentes no alojamento de um tradicional clube de futebol do Rio de Janeiro, cuja faixa etária está entre 14 e 17 anos. Para o levantamento de dados, foi utilizado um questionário estruturado e, para a análise, o modelo metodológico para o cálculo do TPE de estudantes-atletas. Observamos que estudos na área da educação e da educação física insinuam que o tempo de dedicação aos treinamentos esportivos concorrem com o tempo escolar e o prejudicam. Os resultados do nosso estudo sugerem que o problema da redução do TPE dos estudantes-atletas é provocado pelo descumprimento e pela flexibilização das normas escolares por parte da própria instituição escolar.
\end{abstract}

Palavras-chave: Dupla carreira, educação, esporte, tempo de permanência na escola, estudantes-atletas.

\section{EDUCATION AND SPORT: ANALYZING THE SCHOOL TIME OF SOCCER STUDENT-ATHLETE}

ABSTRACT: This paper aims to analyze the Time Spent in School (TSS) of students-athletes of soccer, from an analysis model proposed by Neri (2009). The variable time was used to verify the investment of the student-athlete in the dual career. We conducted a research with 62 student-athletes residing in the accommodation of a traditional soccer club in Rio de Janeiro, whose age were between 14 and 17 years

\footnotetext{
${ }^{1}$ Esta pesquisa contou com apoio e financiamento da CAPES, através da bolsa de doutoramento concedida ao primeiro autor; e das agências de formento CNPq; e FAPERJ.

${ }^{2}$ Colégio Pedro II. Rio de Janeiro, Rio de Janeiro (RJ), Brasil. < hrocha.ufrj@gmail.com>

3 Universidade Estácio de Sá e Centro Universitário São José. Rio de Janeiro, Rio de Janeiro (RJ), Brasil.

$<$ leonardo.melo@globo.com>

${ }^{4}$ Colégio Pedro II. Rio de Janeiro, Rio de Janeiro (RJ), Brasil. <miguelcosta.ef@gmail.com>

${ }^{5}$ Universidade Federal do Rio de Janeiro. Rio de Janeiro, Rio de Janeiro (RJ), Brasil. <ajgsoares@gmail.com>
} 
old. The data were obtain through a survey using a structured questionnaire and analyzed by adapting the methodological model of Neri (2009) to calculate the TSS. We observed that studies in the area of education and physical education suggest that the time dedicated to sports training competes and damage the time dedicated to school. The results of our study suggest that the problem of the reduction of the TSS by student-athletes is caused by non-compliance and flexibility in school rules by the school institution itself.

Keywords: Dual career, education, sport, time spent in school, student-athletes.

\section{EDUCACIÓN Y DEPORTE: ANÁLISIS DEL TIEMPO ESCOLAR DEL ESTUDIANTE-ATLETA DE FÚTBOL}

RESÚMEN: El artículo analiza el Tiempo de Estancia en la Escuela (TEE) de estudiantes-atletas de fútbol a partir de un modelo de análisis propuesto por Neri (2009). La variable tiempo nos sirvió para verificar la inversión del estudiante-atleta en la carrera deportiva dual. Realizamos la investigación con 62 estudiantes-atletas que residían en el alojamiento de un tradicional club de fútbol en Rio de Janeiro, cuyo grupo de edad tiene entre 14 y 17 años. La encuesta se realizó a través de un cuestionario estructurado y analizamos los datos adaptando el modelo metodológico de Neri (2009) para calcular el TEE de los estudiantes-atletas involucrados. Observamos que los estudios en el área de educación y educación física sugieren que el tiempo dedicado al entrenamiento deportivo compite y perjudica el tiempo escolar. Sin embargo los resultados de nuestro estudio sugieren que el problema de reducción del TEE de los estudiantes-atletas es causado por el incumplimiento y la flexibilidad de las reglas escolares por la própria escuela.

Palabras clave: Carrera dual, educación, deporte, tiempo de estancia en la escuela, estudiantes-atletas.

\section{INTRODUÇÃO}

Neste artigo, o tema da dupla carreira esportiva é tratado com o objetivo de entender como estudantes-atletas conseguem conciliar as obrigações educacionais com as rotinas de treinamento, competições e viagens. Esse tema é fruto de um fenômeno social que atinge uma parcela da juventude que busca uma formação, quiçá uma carreira, no esporte. A dupla carreira esportiva, por definição, é a forma como os indivíduos e as instituições se organizam em torno de um projeto de carreira que envolve ao menos duas frentes com suas respectivas demandas e obrigações: a escolarização e a formação esportiva (EUROPEAN COMMISSION, 2007). Consideramos assim que, uma vez que há grandes exigências para ingressar e permanecer nas instituições esportivas, a escolarização de atletas gera dilemas e dificuldades para as instituições escolares, para os atletas e suas famílias.

As pesquisas no Brasil e em diversos países apresentam resultados que refletem uma preocupação latente em relação aos casos de estudantes-atletas que almejam a profissionalização no esporte (SOUZA et. al., 2008; MELO, 2010; MELO, SOARES, ROCHA, 2014; MELO et. al., 2016; ROCHA, 2013, 2017; SOARES, ROCHA, COSTA, 2011; SOARES et. al., 2013; CORREIA, 2014; COSTA E SILVA, 2016). O tempo de dedicação às rotinas no esporte e na escola é amplamente discutido nas pesquisas sobre dupla carreira esportiva, motivando orientações para políticas de gestão dessa população de estudantes-atletas inseridos no esporte de alto rendimento em concomitância com a vida acadêmica (BLODGETT, SCHINKE, 2015; CHRONI, DIAKAKI, PAPAIOANNOU, 2013; METSÄ-TOKILA, 2002; TSHUBE, FELTZ, 2015; MATEU, VILANOVA, INGLÉS, 2018). 
A temática envolvendo a dupla carreira esportiva trata da gestão das atividades do estudanteatleta, buscando estratégias de conciliação das tarefas inerentes à formação esportiva e às da formação acadêmica (escola/universidade). No Brasil, os resultados dos estudos sobre dupla carreira sugerem que o tempo de dedicação ao esporte, tanto no futebol como em outras modalidades esportivas, concorre com o tempo de investimento na escola básica (MELO, 2010; MELO, SOARES, ROCHA, 2014; MELO et. al., 2016; ROCHA, 2013, 2017; SOARES et. al., 2013). Os estudos citados tratam de abordar a gestão do tempo da escola e do esporte a partir de análises, quantitativas e/ou qualitativas, que descrevem tanto o tempo médio gasto pelos estudantes-atletas, quanto o tipo de investimento dedicado às duas instituições.

Procurando compreender a conciliação das rotinas na dupla carreira, a pesquisa de Melo (2010) apontou que estudantes-atletas de futebol no Estado do Rio de Janeiro elaboravam estratégias que podiam variar desde a flexibilização das normas regulares da escola até a troca de instituições escolares, buscando escolas que flexibilizassem as normas para favorecer a permanência do estudante no esporte. Apesar da jornada escolar desses estudantes-atletas ser muito similar ao tempo de permanência na escola dos estudantes não atletas do Estado do Rio de Janeiro, Melo (2010) indicou que esta condição era conquistada à custa de mecanismos de leniência das instituições escolares com os estudantes-atletas.

A análise das pesquisas mostra que a tendência dos trabalhos sobre dupla carreira esportiva é a de encarar o esporte e a escola como instituições concorrentes, com rotinas quase que incompatíveis (SOUZA et. al., 2008; MELO, 2010; MELO, SOARES, ROCHA, 2014; MELO et. al., 2016; COSTA, 2012; COSTA E SILVA, 2016; SOARES et. al., 2013). É possível perceber que os estudos acerca desse tema se preocupavam em buscar uma relação de dependência entre as duas rotinas, a esportiva e a escolar. O problema é que a orientação dos estudos realizados até o momento isolava o esporte das questões que envolvem as relações sociais mais amplas e o colocava como obstáculo à dedicação à escola. Dessa forma, ao encarar o esporte como variável independente que afetaria de alguma maneira a rotina escolar, essas investigações criavam uma espécie de viés interpretativo, indicando que a maneira de conciliar a dupla carreira no esporte e na escola passaria pela flexibilização do currículo e das obrigações escolares.

Considerando ainda que o sistema educacional brasileiro sofre duras críticas acerca da sua organização curricular, seu viés acadêmico e a perpetuação das desigualdades de oportunidades escolares (SCHWARTZMAN, 2011, 2016; RIBEIRO, 2009, 2011; CARDOSO, 2013), devemos atentar ao problema da dupla carreira, uma vez que esses estudantes-atletas são afetados pelos problemas do sistema educacional brasileiro e ainda têm de se ajustar às demandas da formação acadêmica e esportiva.

Nesse sentido, utilizamos a variável tempo como alicerce fundamental para tratarmos os dados desta pesquisa, indicando possíveis consequências de um investimento na dupla carreira: futebolescolarização. Estamos lidando com estudantes-atletas que se dedicam ao futebol com o objetivo de alcançar o alto nível profissional na carreira esportiva e suas expectativas acadêmicas não vão muito além do cumprimento da escolarização obrigatória. Por consequência, o presente artigo trata da análise do Tempo de Permanência na Escola (TPE) de estudantes-atletas de futebol, a partir do modelo de cálculo de Neri (2009), considerando também os tempos de deslocamento, comparando-os com o tempo de treinamento no esporte. $\mathrm{O}$ estudo busca assim demonstrar como ocorre a conciliação entre a rotina de treinamento e competições com a rotina escolar a partir de sua dimensão objetiva. A utilização e adaptação desse modelo busca avançar na análise sobre a permanência na escola dos estudantes-atletas de forma mais próxima de suas experiências nestas instituições.

Partimos do pressuposto de que a organização harmoniosa das rotinas da dupla carreira pode criar oportunidades e transições mais satisfatórias para os atletas nos períodos dentro e fora do esporte. Estudos como o de López de Subijana e Equiza Vaquero (2018); Pato, Isidori e Calderón (2017); e Rodríguez Martínez, Cruz e Torregrosa (2017) sugeriram que políticas públicas ou institucionais permitiriam maior êxito no processo de desenvolvimento holístico da formação do atleta em dupla carreira. Portanto, considerando os aspectos individuais (psicossociais) e coletivos (acadêmicos, esportivos, financeiros etc.), pensamos que o investimento equilibrado na dupla carreira pode ser dependente de uma ação conjunta entre clube, escola, família e atores que coadunam com o projeto em desenvolvimento do estudante-atleta. Nesse sentido, a variável tempo pode ser um elemento central para compreendermos o equilíbrio na dedicação à dupla carreira. 


\section{PARTICIPANTES DO ESTUDO}

O presente estudo investigou 62 jovens das categorias sub-15 e sub-17 (atletas com idade igual ou inferior a 15 e 17 anos, respectivamente), residentes, em regime de albergamento, no alojamento de um clube de futebol de grande prestígio no Rio de Janeiro e detentor do Certificado de Clube Formador (CCF).

O CCF é o selo concedido pela Confederação Brasileira de Futebol (CBF) aos clubes que respeitam os direitos fundamentais do estudante-atleta, fornecendo apoio e atenção à saúde, à escolarização, ao convívio familiar etc. Esse certificado é uma consequência da reforma na Lei Pelé (BRASIL, 1998), que deu novos significados aos dispositivos legais e instituiu mecanismos compensatórios aos clubes que comprovassem investimentos na formação do atleta (BRASIL, 2011).

A coleta de dados ocorreu no ano de 2015, nos meses de outubro e novembro, o que trouxe algumas particularidades, pois outubro foi o mês de retorno dos estudantes-atletas de uma viagem internacional. A viagem para a Europa tirou os estudantes-atletas da categoria sub-17 por um longo período das obrigações escolares e, portanto, foram relativizadas algumas análises que levavam em consideração o tempo de permanência na escola.

\section{TEMPO DE PERMANÊNCIA NA ESCOLA}

O ponto elementar para o desenvolvimento deste estudo foi tomar a variável tempo como eixo comparativo, considerando a estimativa das pesquisas sobre dupla carreira esportiva acerca da importância de tal variável. Tanto no esporte, quanto na escola, o tempo de dedicação às tarefas na dupla formação é entendido como essencial para que os estudantes-atletas atinjam o sucesso pretendido em ambas as carreiras. Encaramos o tempo como variável de duas maneiras distintas, sendo estas: (1) a jornada escolar e (2) o tempo de permanência na escola, conforme o modelo utilizado por Neri (2009) no estudo intitulado "Tempo de Permanência na Escola" (TPE).

O cálculo do TPE leva em consideração a construção de três índices para gerar o índice de referência para as contas finais, sendo estes o Índice de Matrícula (IM), o Índice de Frequência (IF) e o Índice de Jornada Escolar (IJ).

O IM leva em conta o total de alunos em idade escolar e a quantidade deles que se encontram matriculados em uma instituição de ensino. Dessa forma, a razão entre o Número de Matriculados (NM) e o número condicionado ao Universo (U) de indivíduos em idade escolar representa o Índice de Matrícula. Essa equação é representada matematicamente como:

$$
\mathrm{IM}=\frac{\mathrm{NM}}{\mathrm{U}}
$$

Para a composição do TPE, temos de levar em consideração o IF. Esse indicador é calculado a partir da quantidade de Dias Letivos (DL) que o estudante teve durante um mês e quantas vezes ele foi à escola nesse período. Primeiro, considera-se um período e, a partir dele, indicam-se quantos dias letivos houve nesse período. Em seguida, pergunta-se ao entrevistado quantas faltas ele teve nesse período demarcado. No final, subtrai-se o Número de Faltas (NF) do número de dias letivos e calcula-se a razão entre o resultado desta subtração e o número de dias letivos existentes no período de referência, conforme a equação abaixo:

$$
\mathrm{IF}=\frac{(\mathrm{DL}-\mathrm{NF})}{\mathrm{DL}}
$$

O Índice de Jornada Escolar (IJ) é construído a partir de uma Jornada de Referência (JR) que Neri (2009) utilizou em seus cálculos. Essa Jornada de Referência é de 5 horas. Para fins de calcular o IJ, basta dividir a Jornada Escolar declarada (JE) pelos estudantes-atletas pela JR. 


$$
\mathrm{IJ}=\frac{\mathrm{JE}}{\mathrm{JR}}
$$

A última etapa que antecede à elaboração do Tempo de Permanência na Escola é a construção do Índice de Permanência na Escola (IPE). Esse indicador é elaborado a partir da multiplicação dos três índices anteriores. O resultado dessa equação mostrará um valor que deverá ser multiplicado novamente pela jornada de referência de 5 horas para chegarmos ao dado sobre o tempo de permanência na escola. O IPE é o resultado da equação que multiplica o IF pelo IM e pelo IJ.

$$
\mathrm{IPE}=\mathrm{IM} \times \mathrm{IF} \times \mathrm{IJ}
$$

Para o cálculo do tempo de permanência na escola, o IPE, deverá ser multiplicado pela jornada de referência de 5 horas e, assim, atingiremos o valor do tempo de permanência na escola, conforme a equação adiante:

$$
\mathrm{TPE}=\mathrm{IPE} \times \mathrm{JR}
$$

\section{Tempo de deslocamento para a escola e para o treino}

O tempo de deslocamento para a escola e para o treino foi calculado a partir da declaração do estudante-atleta. Questionamos a estimativa de tempo que o estudante-atleta demorava para sair do alojamento do clube até chegar à escola ou ao local de treinamento.

\section{Jornada de treinamento}

Para o levantamento do dado da jornada de treinamento, também perguntamos aos estudantes-atletas em qual horário era habitual iniciar a rotina de treinamento e em qual horário tais sessões terminavam. A diferença entre os valores forneceu a Jornada de Treinamento (JT).

O tratamento dado à JT não foi o mesmo aplicado ao Tempo de Permanência na Escola. Justifica-se esse ajuste metodológico em função dos seguintes argumentos sobre o contexto: (1) como todos treinavam, o índice de matrícula seria igual a 1; (2) as ausências no treinamento eram sempre por motivos relacionados ao esporte, como tratamento das lesões, participação em jogos ou treinamentos em outras categorias etc. Logo, o índice de frequência também seria igual a 1; e (3) não há uma jornada de referência para estimativas do índice de jornada de treinamento. Pelas razões citadas, podemos considerar a Jornada de Treinamento igual ao Tempo de Permanência no Treino.

\section{Aspectos éticos}

Todas as entrevistas e o preenchimento dos questionários foram feitos por um pesquisador, obedecendo aos critérios éticos de pesquisas com seres humanos. Os participantes foram informados sobre os riscos e benefícios da pesquisa, e foi obtida autorização dos responsáveis pelo clube para a realização das fases do trabalho mediante o termo de consentimento livre e esclarecido (Parecer $\mathrm{n}^{\circ}$ 131/2010, aprovado pelo Comitê de Ética da Universidade Gama Filho).

\section{RESULTADOS}

Os 62 atletas entrevistados correspondiam ao total de estudantes-atletas residentes no clube à época da pesquisa e os questionários foram aplicados a todos os residentes. Assim, o estudo tratou especificamente do grupo de estudantes-atletas alojados no centro de treinamento do clube, portanto, não se deve generalizar os achados para toda a população de estudantes-atletas do futebol brasileiro. 
Todavia, esse é um caso que não se limita ao clube estudado, pois, há, no modelo de formação no futebol, muitos clubes no Brasil que adotam o regime de albergamento dos atletas das categorias de base.

Do total de jovens participantes do estudo, 57 estavam regularmente matriculados na escola no momento da pesquisa. No caso da categoria sub-15, o número de atletas investigados foi de 24 e o total de atletas matriculados foi de 22 jovens. Para a categoria sub-17, o número total de atletas investigados foi de 38, sendo que apenas três não estavam matriculados no momento da pesquisa. Destaca-se que, nessa categoria, um atleta já havia terminado o ensino médio no período da coleta dos dados e, portanto, não era mais estudante na educação básica e também não cursava o ensino superior.

Em relação ao turno de estudo dos estudantes-atletas, verificamos que os alunos das categorias com maior idade tenderam a ingressar no ensino noturno (Gráfico 1).

Gráfico 1. Frequência de turno escolar por categoria.

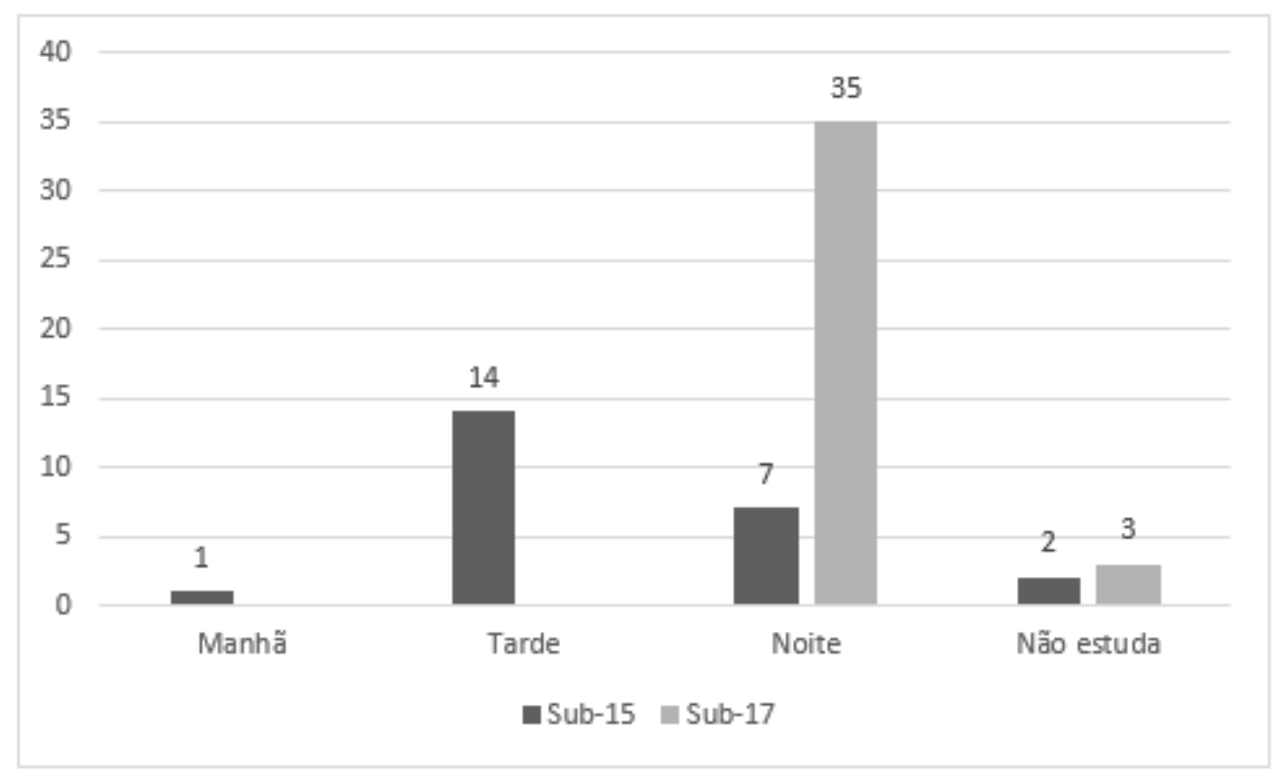

Fonte: Elaborado pelos autores.

No grupo de estudantes-atletas investigados nas categorias de base do futebol, observamos que o Índice de Matrícula não foi igual a 1, o que mostrou que nem todos estavam regularmente matriculados na escola no momento em que os dados foram coletados. Isso se justifica pelo fato de que alguns dos estudantes-atletas haviam chegado ao clube na semana em que foram entrevistados, não tendo assim tempo hábil para que regularizassem a matrícula em uma instituição de ensino. Uma das características da formação no futebol é a intensa migração de atletas entre clubes, cidades e estados (Tabela 1).

Tabela 1: Índices de Matrícula

\begin{tabular}{lc}
\hline Categoria & Índices de Matrícula \\
\hline Sub-15 & 0,916666667 \\
Sub-17 & 0,921052632 \\
Geral & 0,919354839 \\
\hline
\end{tabular}

Fonte: Elaborada pelos autores.

Para elaboração do IF, utilizamos um mês de referência com 30 dias corridos e 22 dias letivos, desconsiderando os fins de semana. Destaca-se que essa adaptação para o período de referência foi necessária, pois o período de aplicação do questionário variou em dois meses e, em ambos os casos, 
alguns atletas haviam participado de uma viagem para competições internacionais. Se ainda fosse considerado o feriado de 7 de setembro, por exemplo, o número de dias letivos em setembro de 2015 cairia de 22 para 21, o que não alteraria o cálculo final. Além disso, por estarmos tratando de um grupo de 62 estudantes-atletas, o Número de Faltas utilizado na base final dessa equação foi equivalente ao número médio de faltas declaradas pelos estudantes-atletas.

No grupo geral, o Índice de Frequência foi de IF = 0,729472141, com média de faltas de, aproximadamente, 5,95 dias. O número médio de faltas dos atletas da categoria sub-15 foi de aproximadamente 5,29 dias no período de referência, produzindo um Índice de Frequência igual a IF = 0,759469697 . Na categoria sub-17, que realizou a viagem internacional, o número médio de faltas foi de 6,37 dias, gerando um Índice de Frequência igual a IF = 0,710526316 (Tabela 2).

Tabela 2: Índices de Frequência

\begin{tabular}{lc}
\hline Categoria & Índices de Frequência \\
\hline Sub-15 & 0,759469697 \\
Sub-17 & 0,710526316 \\
Geral & 0,729472141 \\
\hline
\end{tabular}

Fonte: Elaborada pelos autores.

Os dados da pesquisa mostraram que a Jornada Escolar média dos estudantes-atletas de futebol é de 3 horas, 24 minutos e 45 segundos, tornando o IJ = 0,6825. Na categoria sub-15, a Jornada Escolar média foi maior, atingindo um valor de 3 horas, 52 minutos e 42 segundos, fazendo o IJ para essa categoria de base ser igual a 0,775666667. Verificou-se o menor valor médio de Jornada Escolar na categoria sub-17, na qual a quantidade de horas de aula que um estudante-atleta teve na escola foi de 3 horas, 7 minutos e 6 segundos. Esse valor se refletiu em um IJ = 0,623666667 (Tabela 3).

Tabela 3: Índices de Jornada

\begin{tabular}{lc}
\hline Categoria & Índices de Jornada \\
\hline Sub-15 & 0,775666667 \\
Sub-17 & 0,623666667 \\
Geral & 0,6825 \\
\hline
\end{tabular}

Fonte: Elaborada pelos autores.

Assim, multiplicando os dados indicados anteriormente, elaborou-se o IPE (Tabela 4).

Tabela 4: Índice de Permanência na Escola (IPE)

\begin{tabular}{lcccc}
\hline Categoria & $\begin{array}{c}\text { Índices de } \\
\text { Matrícula }\end{array}$ & $\begin{array}{c}\text { Índices de } \\
\text { Frequência }\end{array}$ & $\begin{array}{c}\text { Índices de } \\
\text { Jornada }\end{array}$ & $\begin{array}{c}\text { Índice de Permanência na } \\
\text { Escola }\end{array}$ \\
\hline Sub-15 & 0,916666667 & 0,759469697 & 0,775666667 & 0,540004051 \\
Sub-17 & 0,921052632 & 0,710526316 & 0,623666667 & 0,408147507 \\
Geral & 0,919354839 & 0,729472141 & 0,6825 & 0,457714354 \\
\hline
\end{tabular}

Fonte: Elaborada pelos autores.

O valor final do Tempo de Permanência na Escola (TPE) dos estudantes-atletas foi obtido através da multiplicação do IPE por 5, resultando em: (1) para o grupo total de atletas, o TPE foi de aproximadamente 2,29 horas, ou 2 horas 17 minutos e 24 segundos; (2) na categoria sub-15, o TPE foi de aproximadamente 2,7 horas, ou 2 horas e 42 minutos; e (3) na categoria sub-17, o TPE foi de aproximadamente 2,04 horas, 2 horas 2 minutos e 24 segundos (Gráfico 2). 
Gráfico 2: Tempo diário de jornada escolar e Tempo de Permanência na Escola diário por categoria.

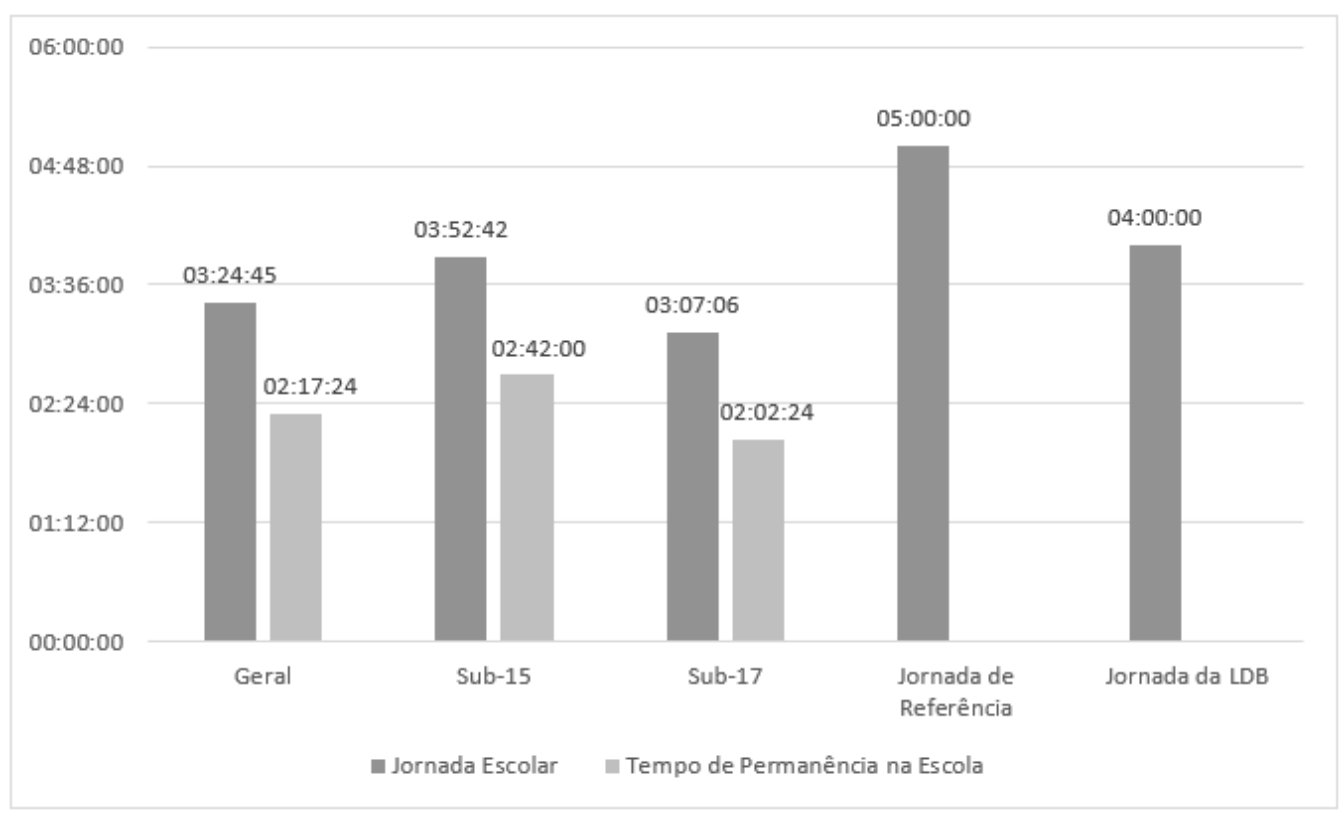

Fonte: Elaborado pelos autores.

O TPE mostrou-se muito inferior à Jornada Escolar declarada pelos estudantes-atletas. Esta diferença foi atribuída a dois índices: (1) o que se refere à frequência dos estudantes-atletas; e (2) o que concerne à própria Jornada Escolar.

O Gráfico 3 mostra uma realidade diferente para os estudantes-atletas das categorias sub-15 e sub-17 relativa ao tempo de deslocamento para a escola e para o treino. Enquanto o tempo de deslocamento para os treinamentos é quase inalterável, quando se trata da escola, o valor para a categoria com idade maior aumenta consideravelmente. Isso se justifica pelo fato de a escola onde estudavam os atletas da categoria sub-17 ficar mais distante da sede do clube onde residiam.

Gráfico 3: Tempo médio de deslocamento diário por categoria.

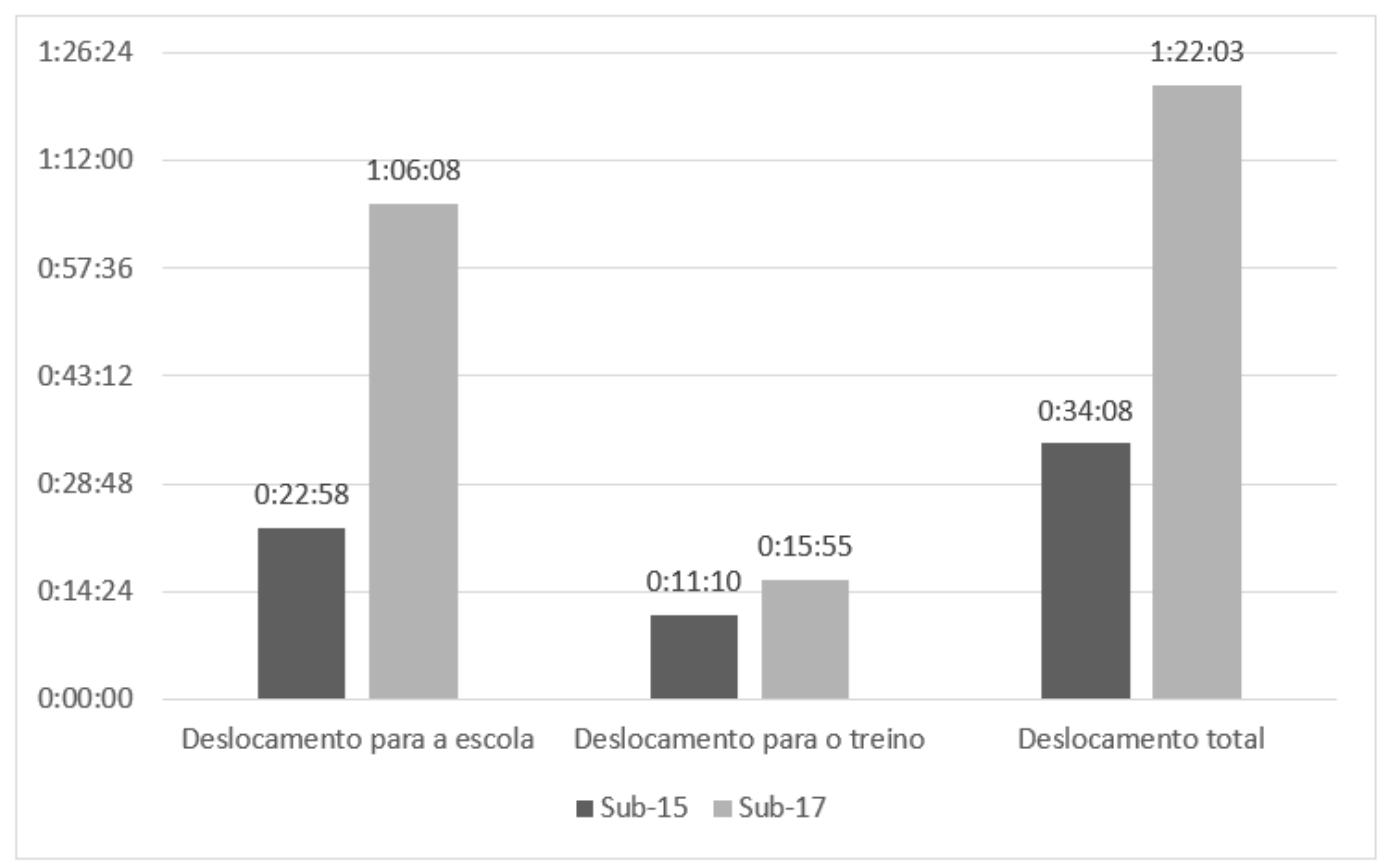

Fonte: Elaborado pelos autores. 
A Jornada de Treinamento, que se inicia nas primeiras horas do dia, por volta das 8 horas e 30 minutos de cada manhã, chega ao seu fim às 11 horas. Em média, o tempo gasto para se dedicar aos treinamentos atinge um total de 2 horas, 33 minutos e 28 segundos. Na categoria sub-15, o tempo médio gasto nos treinos é de 2 horas, 33 minutos e 45 segundos e, na categoria sub-17, a jornada de treinamento é de 2 horas, 33 minutos e 17 segundos. Observou-se que o tempo de treinamento nas categorias sub-15 e sub-17 não se alteram significativamente. O tempo médio gasto com o treinamento, comparado com a Jornada Escolar declarada pelos estudantes-atletas, pode indicar que a concorrência entre um e outro não seja tão acirrada.

Comparando a Jornada Escolar declarada com a Jornada de Treinamento, observou-se que a segunda permanece praticamente constante, enquanto a primeira sofre algumas variações. Na média geral, para ambos os casos, a diferença entre a JE e a JT é menos de 1 hora (51 minutos e 17 segundos). $\mathrm{Na}$ categoria sub-17, a diferença média entre a JE e a Jornada de Treinamento declarada tem o cenário com pior rendimento: a diferença entre as duas variáveis é de 33 minutos e 49 segundos. Na categoria sub-15, a diferença entre a JE e a JT é de 1 hora, 18 minutos e 57 segundos. (Gráfico 4)

Gráfico 4. Tempo médio diário de Jornada Escolar e Jornada de Treinamento por categoria.

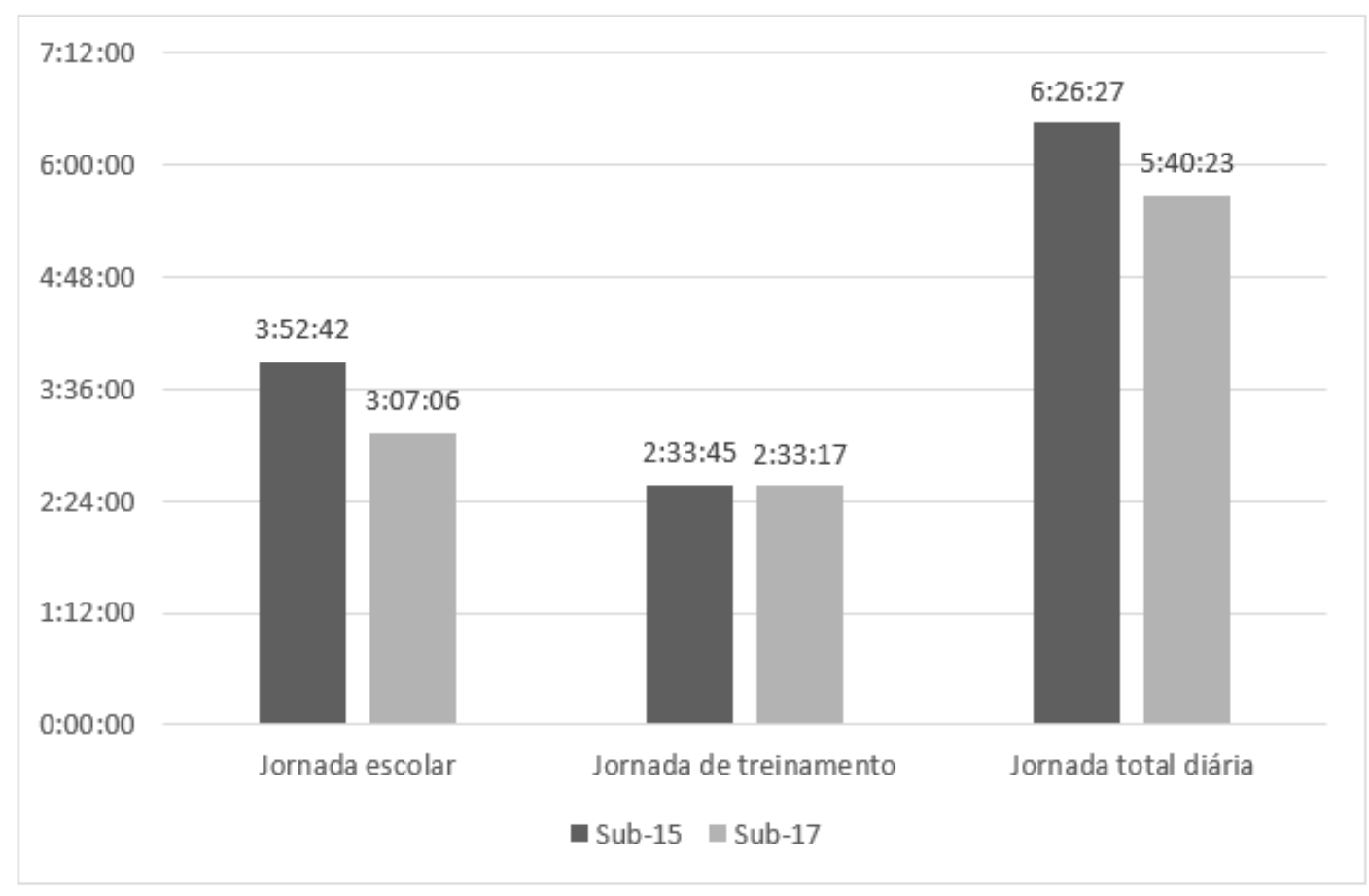

Fonte: Elaborado pelos autores.

O panorama ainda sofre algumas alterações quando se consideram os dias da semana em que essa jornada é posta em prática. Para a escola, os atletas dedicam cinco dias na semana, porém, para o treinamento e competições, a quantidade de dias dedicados a essa atividade pode chegar a seis por semana. Assim, a jornada semanal de envolvimento com atividades ligadas ao futebol é similar à jornada semanal de dedicação aos bancos escolares. (Gráfico 5). 
Gráfico 5: Tempo médio semanal de Jornada Escolar e Jornada de Treinamento por categoria.

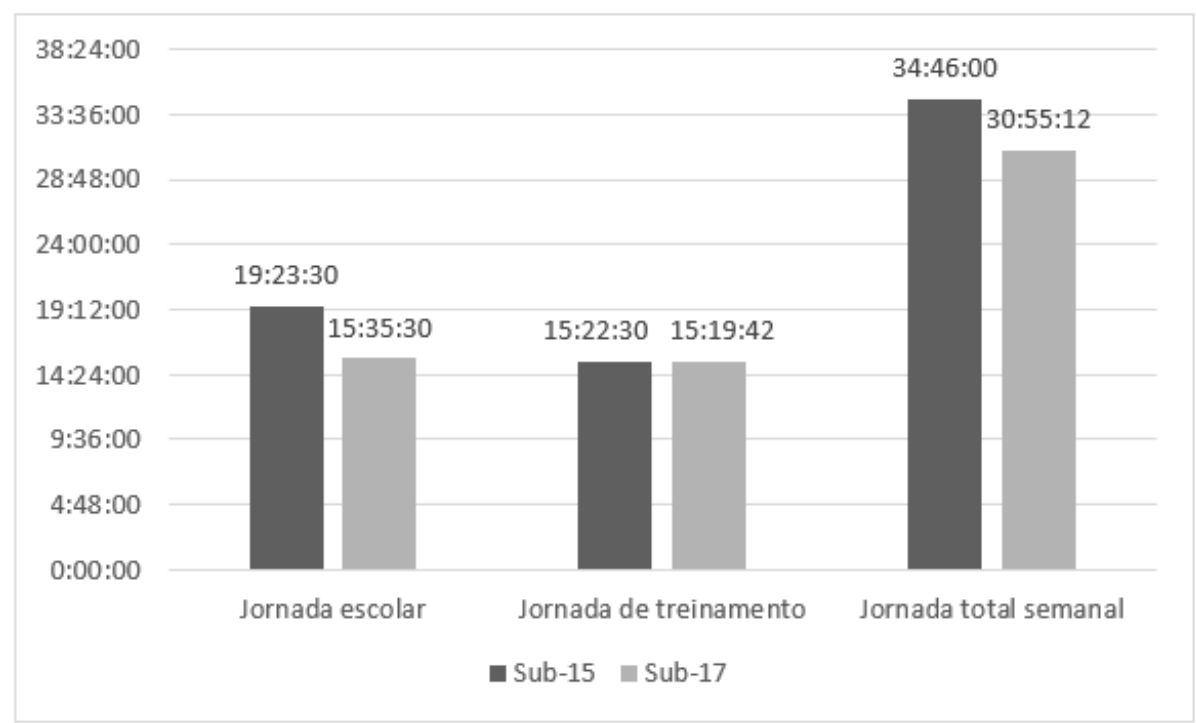

Fonte: Elaborado pelos autores.

O Gráfico 6 mostra a comparação entre a Jornada de Treinamento e o Tempo de Permanência na Escola. O TPE só supera a JT na categoria sub-15, mesmo assim com uma diferença relativamente pequena de 8 minutos e 15 segundos. No geral, a diferença entre a JT e o TPE foi de 16 minutos e 4 segundos a favor da JT. Na categoria sub-17, verificamos uma diferença entre a JT e o TPE de aproximadamente 30 minutos e 53 segundos a mais na JT.

Gráfico 6: Tempo médio diário de Jornada de Treinamento vs Tempo de Permanência na Escola

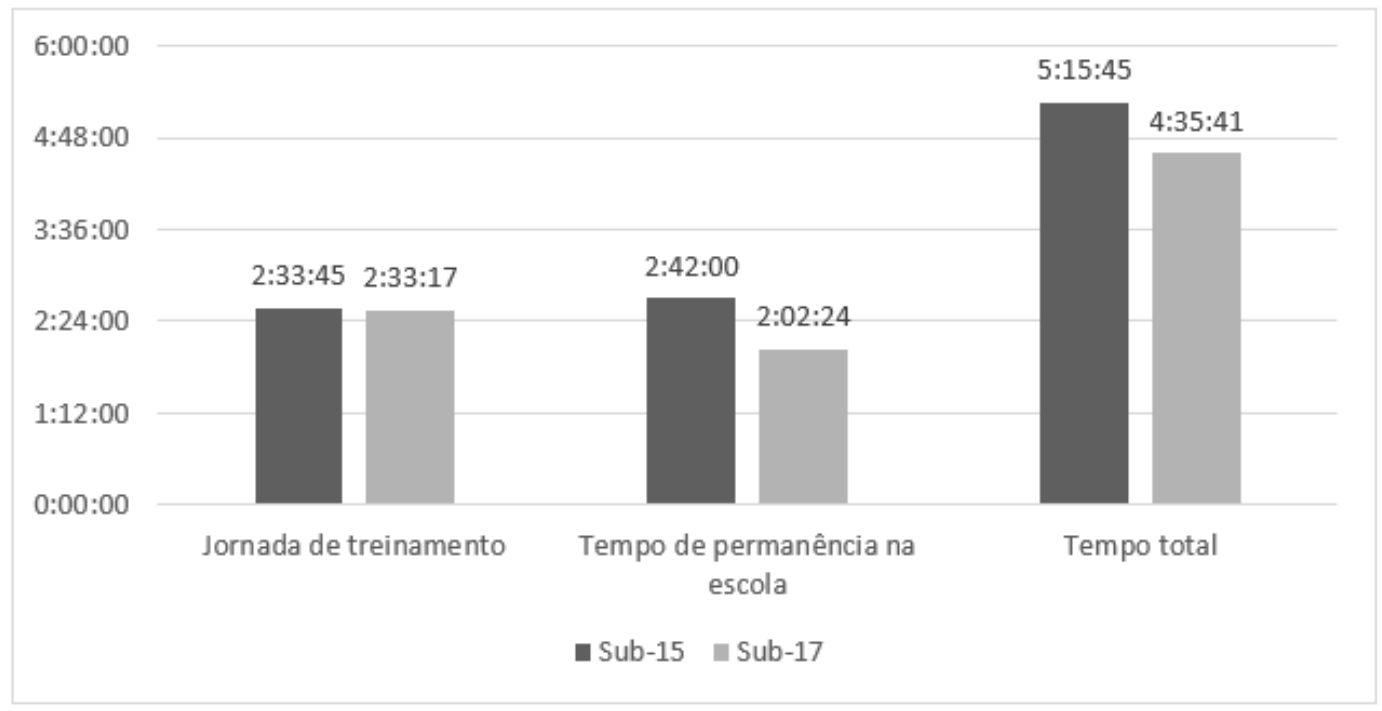

Fonte: Elaborado pelos autores.

No Gráfico 7, observamos que a Jornada de Treinamento semanal girou em torno das 15 horas de dedicação ao futebol para todas as categorias. Por outro lado, a escola perdeu espaço conforme o estudante-atleta se aproximava da profissionalização no futebol. Ao se comparar a diferença entre a JT semanal e o TPE por semana, verificou-se uma configuração completamente desfavorável à instituição de ensino: (1) na média geral, a diferença entre a JT e o TPE dedicado durante a semana é igual a 3 horas, 53 minutos e 48 segundos; (2) na categoria sub-15, a diferença é menor entre as variáveis comparadas, 
atingindo um valor de 1 hora, 52 minutos e 30 segundos; e (3) a categoria sub-17 apresenta o cenário mais impactante, em que a diferença entre a jornada semanal de treinamento e o tempo semanal de permanência na escola alcança um valor de 5 horas, 7 minutos e 42 segundos.

Gráfico 7: Tempo médio semanal de Jornada de Treinamento vs Tempo de Permanência na Escola

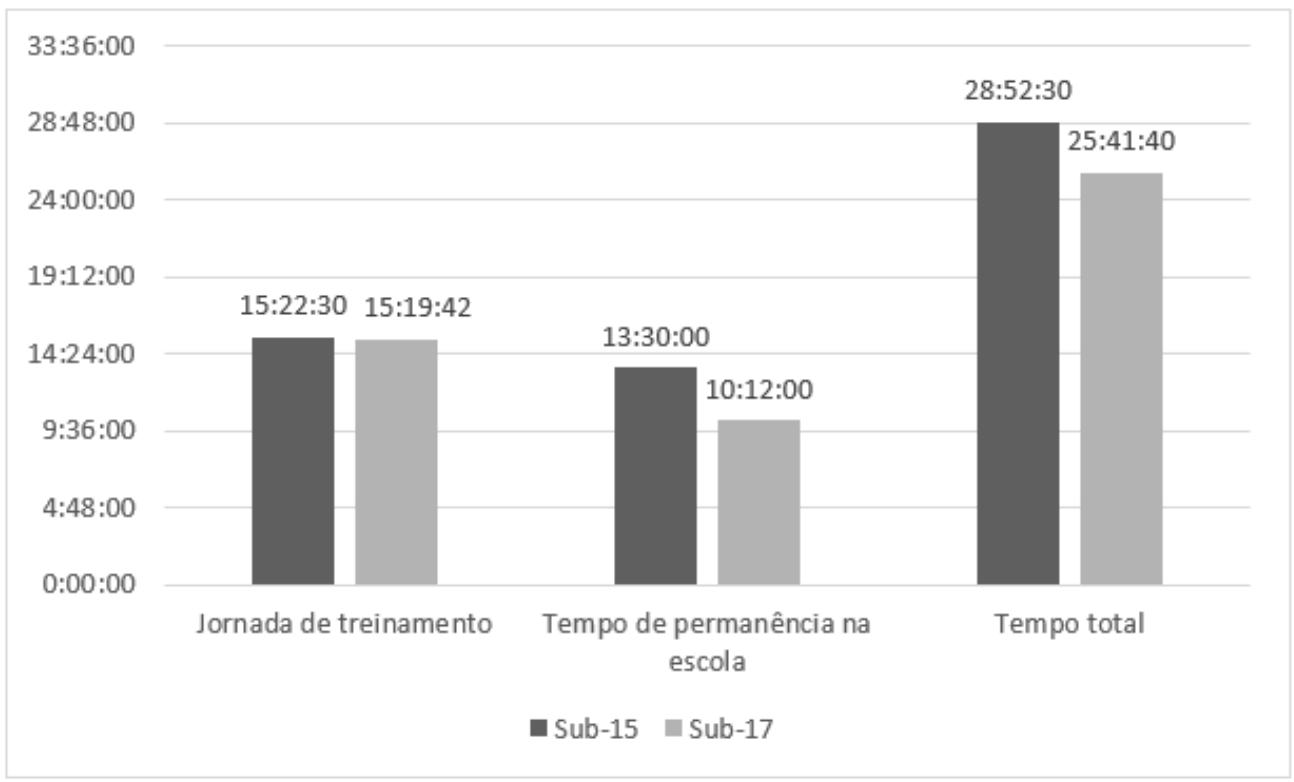

Fonte: Elaborado pelos autores.

\section{DISCUSSÃO}

O estudo indicou que o TPE do estudante-atleta de futebol pode ser afetado tanto por sua Frequência, quanto pela Jornada Escolar das instituições de ensino onde estão matriculados. Considerando o que foi apresentado por Soares et. al. (2013), que indicaram que a Jornada Escolar do estudante-atleta de futebol do Estado do Rio de Janeiro era similar a dos demais estudantes não atletas, o teste do novo modelo de análise do TPE, que leva em conta e detalha outros índices na composição dessa medida, demonstra que, no caso brasileiro, a permanência na escola pode ser ainda mais afetada quando relacionada ao esporte.

Observemos que o fato de ter reduzido a análise a um único clube e com uma amostra restrita a atletas em regime de albergamento nos permitiu identificar que a redução do TPE pode ocorrer devido a problemas de gestão da escola noturna e mesmo da forma de construção da identidade dos estudantesatletas com o processo de escolarização (COSTA, 2011; CORROCHANO, 2013). Os resultados indicaram que o TPE dos estudantes-atletas de futebol é negativamente afetado por dois indicadores: (1) a frequência escolar dos estudantes-atletas; e (2) a jornada escolar reduzida na escola noturna. Embora possamos sugerir que tal processo de migração para o ensino noturno decorre das demandas do futebol (MELO, 2010), em tese, se tivéssemos uma igualdade nas estruturas e na organização das rotinas escolares por parte das instituições de ensino, não deveríamos ter uma disparidade relevante (cerca de 45 minutos) entre a jornada escolar no período da tarde e a jornada escolar no turno da noite.

Se observarmos o Gráfico 1, quando apresentamos o turno escolar em que os estudantesatletas estavam matriculados, é possível verificar que a maioria daqueles da categoria sub-17 encontravase na escola noturna. Não obstante, verificamos também no Gráfico 2 que tanto a Jornada Escolar declarada, quanto o TPE dos estudantes-atletas da categoria sub-17 são os menores indicadores levantados por nossa pesquisa. Isso sugere que a JE noturna possui uma redução de tempo escolar para os estudantes-atletas e talvez para os estudantes não atletas quando comparada aos demais turnos de ensino. Mesmo que não signifique diretamente um descompasso da estrutura educacional na escola noturna, podemos supor que essa redução do tempo da jornada escolar acompanhe os desajustes da escola noturna conforme críticas já existentes. Krawczyk (2011) enfatizou que os conteúdos trabalhados 
no turno da noite podem sofrer redução pelo planejamento docente, ainda que alguns professores recorram às mesmas estratégias de ensino adotadas nos outros turnos. Para a autora, em geral, o estudante do turno da noite tem prejuízo acadêmico em ambas as situações: a primeira, por ser privado do aprofundamento dos conteúdos; a segunda, por não ter suas especificidades de estudante da escola noturna atendidas pelos métodos de ensino utilizados.

Outro fator relevante é o modo como se organiza o ensino médio no Brasil. Krawczyk (2011) destaca que essa etapa da educação básica enfrenta o desafio de se tornar mais atraente para o estudante. Além disso, desde a criação do ensino secundário, há o dilema característico entre atingir o objetivo de buscar uma formação geral para o exercício da cidadania e outra específica para inserção no mercado de trabalho (LEÃO, 2018). Essas tensões refletem no projeto da escola para atendimento do estudante e nem sempre são planejadas de modo a atender às especificidades do público-alvo. Os estudantes-atletas relatavam sair da aula antes do horário estimado para o fim das atividades escolares, assim como chegavam após o horário previsto. Seus relatos apontam para a falta e absenteísmo dos professores e para o próprio cansaço físico e mental à noite. Todavia, os problemas que envolvem o ensino noturno estão presentes para todos os estudantes e não somente para os estudantes-atletas. Assim, corroboramos o argumento de Costa (2011) ao indicar que o ensino noturno estruturado no Brasil não atende à especificidade do público que nele ingressa.

Os estudantes-atletas de futebol, no caso estudado, não chegaram a atender a obrigatoriedade de 75\% de frequência como previsto na Lei de Diretrizes e Bases da Educação Nacional (LDB) (BRASIL, 1996). Destaca-se que a especificidade da atividade desenvolvida por tais estudantes, a qual não é ainda reconhecida como uma modalidade de trabalho (ROCHA, 2017), possui características peculiares, tais como a necessidade de executar viagens para as competições e, muitas vezes, não possui amparo legal que sustente o abono das faltas - ou reposição das aulas - motivadas pelas ausências para o exercício destas atividades (GUIDOTTI, CORTIS, CAPRANICA 2015; PATO, ISIDORI, CALDERÓN, 2017; STAMBULOVA, WYLLEMAN, 2019).

O não reconhecimento da atividade esportiva como uma modalidade de trabalho ou estágio de jovens aprendizes para estudantes-atletas coloca-os em uma condição de insegurança jurídica, pois o descumprimento das garantias dos seus direitos fundamentais, como o acesso à e a permanência na escola por exemplo, é analisado a partir da discricionariedade das instâncias jurídicas. Dessa forma, caberia à instituição escolar considerar a condição especial do estudante-atleta como um jovem trabalhador ou aprendiz da profissão de atleta (ROCHA, 2017). Todavia, a falta de uma regulamentação específica para tais casos desampara a escola na justificativa das ausências dos estudantes-atletas e mesmo na produção de tarefas e suportes que venham a suprir lacunas vividas por esses indivíduos na escola. Os acordos entre clube, estudante-atleta e escola são feitos individualmente e nem sempre são favoráveis ao projeto de escolarização do estudante-atleta, assim como raramente garantem que a escola e o clube atenderão às especificidades da sua condição.

A exemplo disso, destaca-se que, do ponto de vista sociológico, a regulamentação de um fato social que vem produzindo desigualdades de oportunidades serviria para disciplinar as instituições e indivíduos envolvidos (BECKER, 2008). O processo de disciplinamento das instituições e dos indivíduos envolvidos na conciliação da dupla carreira do estudante-atleta pode contribuir para o equilíbrio no investimento deles nas demandas geradas pelo esporte e pela educação. López de Subijana e Equiza Vaquero (2018) compararam a trajetória esportiva e educacional de atletas que tiveram investimentos diferentes na dupla carreira, levando em conta o tipo de instituições que frequentaram, a saber: instituições com suporte para a dupla carreira e aquelas que não prestaram qualquer forma de apoio. As autoras concluíram que os estudantes-atletas que frequentaram instituições com suporte para a dupla carreira tiveram menos dificuldades para conciliar as rotinas e planejar as transições de categorias no esporte e sua aposentadoria neste, visando inclusive a reconversão profissional e reinserção no mercado de trabalho ordinário.

Observa-se que o planejamento de políticas públicas ou institucionais pode ser um caminho para amparar as instituições e os indivíduos envolvidos na dupla carreira. Ainda que seja um processo para o ajustamento de condutas, a experiência europeia na regulamentação da dupla carreira vem sugerindo possibilidades de intervenção que podem apresentar caminhos para a gestão das rotinas do estudante-atleta. Emmerick (2019), ao realizar uma revisão dos estudos sobre dupla carreira, identificou 
que as instituições que desenvolviam algum tipo de programa de assessoramento dos estudantes-atletas na comunidade europeia tinham resultados melhores na gestão da dimensão objetiva da dupla carreira, como: organização do tempo; planejamento para os estudos, treinamento e competições; adequação ao calendário de provas; entre outras tarefas inerentes à escolarização e à formação esportiva. Ainda que possamos dizer que a dupla carreira é um fenômeno holístico, que tem influência também nas questões subjetivas (psicossociais) do estudante-atleta, uma consequência latente e representada em vários estudos no Brasil e na Europa é a dificuldade de organização para atender às demandas objetivas das duas carreiras.

Apesar disso, no Senado Federal, há tentativas de regulamentação de ações que busquem a mediação da relação entre o estudante-atleta, o clube e a escola. Os Projetos de Lei no 2.493/2019 (BRASIL, 2019a) e $\mathrm{n}^{\circ}$ 4.393/2019 (BRASIL, 2019b) visam, respectivamente, (1) alterar dispositivos das Leis $n^{\circ}$ 9.394/96 (BRASIL, 1996) e $n^{\circ}$ 12.711/2012 (BRASIL, 2012), com o objetivo de permitir que estudantes-atletas tenham condições para concluir a educação básica sem abandonar o esporte e ainda garantir o acesso ao ensino superior e ao ensino técnico e tecnológico, na modalidade à distância na rede federal de ensino; e (2) permitir o ensino domiciliar ou à distância aos estudantes-atletas ou artistas que estejam em competições ou apresentações de espetáculos distantes das suas instituições de ensino (BRASIL, 2019a, 2019b). Destacamos que, ao contrário das políticas europeias de dupla carreira, os legisladores brasileiros resolveram incluir por analogia os estudantes-artistas, pois a formação artística também cria obstáculos à frequência escolar em função de espetáculos, viagens e ensaios.

Pensamos que essa iniciativa indica que o parlamento brasileiro começa a movimentar o debate sobre a dupla carreira esportiva (e artística) no Brasil, na direção de formular políticas públicas e de regulamentar esta questão, que atinge a uma população específica de nossos jovens. Todavia, tais iniciativas ainda estão em processo de tramitação nas câmaras legislativas, sujeitas a alterações ou a impedimentos nas votações. Ainda assim, os apontamentos apresentados nesses Projetos de Lei não podem prescindir de um debate mais amplo com as instituições esportivas/artísticas, acadêmicas (escola básica e universidade) e com a sociedade em geral, no sentido atender às demandas e às necessidades dos estudantes-atletas ou artistas no Brasil. Ainda estamos longe de um debate mais profundo sobre o tema tal como se iniciou em 2007 na União Europeia (EU) (EUROPEAN COMMISSION, 2007) e se consolidou no "EU Guidelineson Dual Careers of Athletes Recommended Policy Actions in Support of Dual Careers in High-Performance Sport" (EUROPEAN COMISSION, 2012). Esse guia de orientações sugere modelos para realizar a conciliação entre esporte e formação acadêmica, bem como os programas de inserção no mercado de trabalho ordinário após a carreira esportiva.

O discernimento sobre os direitos à educação deve ser acompanhado de reflexão que nos leve a problematizar o projeto de escolarização oferecido pelas instituições educacionais no Brasil. O projeto de escolarização brasileiro tem um caráter propedêutico, que torna a educação básica regular voltada, quase exclusivamente em sua estruturação, à entrada na educação superior (SCHWARTZMAN, 2011). Nesse caso, a educação tem razão em si mesma e, consequentemente, não desempenha o papel de formar sujeitos capazes de desenvolver suas competências individuais e ampliar a sua participação social. Além disso, é gerado um dilema em função deste projeto de escolarização não contemplar os diferentes projetos individuais existentes na escola e nem oferecer um mecanismo de compensação no sentido de, pelo menos parcialmente, abrandar as diferenças sociais refletidas em tratamentos desiguais dispensados na escola.

O sistema educacional brasileiro, além de ter um projeto estandartizado para os indivíduos que nele ingressam, tem outros indicadores que ressaltam as desigualdades de oportunidades educacionais. Schwartzman (2016) observou que:

Um indicador importante da desigualdade de especial interesse para o Brasil, é a quantidade de jovens que abandonam o sistema escolar antes de seu término (dropouts). Comparações internacionais confirmam que o abandono escolar está fortemente relacionado às características socioeconômicas dos estudantes e também à organização dos sistemas escolares. Alunos de famílias mais pobres, menos educadas, vivendo em regiões mais isoladas, tendem a abandonar a escola com mais frequência. Nos países em que a diferenciação do ensino secundário é menor, o acesso ao ensino superior é mais amplo, mas o abandono escolar tende a ser maior. Inversamente, nos países mais diferenciados, as taxas de abandono tendem a ser menores ( $\mathrm{p}$. 26). 
Apesar da citação de Schwartzman (2016) indicar que o abandono escolar pode estar intimamente relacionado às condições socioeconômicas e à organização dos sistemas escolares, não afirmamos necessariamente que os estudantes-atletas da pesquisa fazem parte do grupo de jovens que se evadem da escola. O número de matrículas está bem próximo do ideal e aqueles que não estavam matriculados no momento da pesquisa correspondiam a menos de $10 \%$, cinco estudantes-atletas, do total de atletas alojados, justificando-se a ausência de matrícula por já terem concluído o ensino médio ou por terem recém-ingressado no clube e na cidade no momento da coleta de dados. Porém, as variáveis Jornada Escolar (JE) e Tempo de Permanência Escola (TPE) são dados a serem destacados como pontos negativos, mesmo se tratando dos estudantes-atletas matriculados.

Rocha (2017) apontou que o perfil socioeconômico dos estudantes-atletas de futebol no Rio de Janeiro pertence a famílias com renda familiar equivalente às classes médias, corroborando os achados do estudo de Melo (2010). Assim, poderíamos sugerir que a situação desfavorável para a escolarização desses estudantes-atletas pode estar associada ao nível de organização das instituições de ensino que frequentam e à gestão que o próprio clube faz da carreira destes estudantes. Os dados mostraram que a variável que mais afeta o tempo de permanência na escola é a própria jornada escolar, principalmente, da escola noturna. O descumprimento da normativa legal, ou a leniência dos gestores escolares e/ou do clube, indica que os estudantes-atletas da categoria sub-17, segundo seus próprios depoimentos, possuem um prejuízo de quase 2 horas no seu tempo de permanência na escola quando comparamos ao que a LDB (BRASIL, 1996) exige, ou seja, jornada escolar diária de 4 horas.

Essa redução do tempo de permanência na escola foi discutida por Neri (2009), que associou um maior tempo de dedicação aos bancos escolares com resultados melhores nos testes de proficiência padronizados, como a Prova Brasil e o Exame Nacional do Ensino Médio. Logo, os estudantes-atletas da pesquisa, quando posicionados em disputa nos testes de proficiência com outros estudantes não atletas mais dedicados à escola, estariam, em tese, em condições de desvantagem para o mesmo pleito.

Os dados da pesquisa indicaram que a escola pública noturna do Rio de Janeiro possui um nível de organização tal que a diferencia na quantidade de horas de estudo oferecidas aos seus estudantes, se compararmos os estudantes-atletas das categorias sub-15 e sub-17. Os primeiros, mais novos, estudam no período da tarde, os de maior idade, à noite. Isso sugere que o ensino noturno é encarado com menos rigor que o ensino vespertino. Ao taxarmos o tempo de permanência na escola noturna como sendo inferior ao do turno da tarde, sendo isso decorrente quase que exclusivamente do não cumprimento da jornada exigida pela legislação, sugerimos que tal diferenciação pode contribuir para potencializar as desigualdades de oportunidades de acesso aos meios de profissionalização pelas vias escolares. O tempo de permanência na escola pode ser um fator importante para aumentar o rendimento dos estudantes nos testes de proficiência (NERI, 2009). Ao indicarmos a deficiência no ensino noturno, devemos destacar que esse tipo de ensino é secundarizado ou desvalorizado pela própria instituição escolar (COSTA, 2011). Embora os dados mostrem que tal processo de migração para o ensino noturno decorre mais das demandas do futebol que das trajetórias escolares acidentadas dos estudantes-atletas (SOARES et al. 2013), observamos que a desigualdade organizacional entre a escola vespertina e a noturna pode ser o fator que melhor explica a redução da jornada escolar no período da noite.

Costa (2011) teceu uma crítica às experiências públicas e privadas de ensino noturno, enfatizando a falta de sistematização e a ausência de mecanismos que permitam o funcionamento adequado deste tipo de formação para o grupo atendido. Assim, aqueles que não obtiveram instrução formal no período obrigatório de escolarização são deslocados para instituições cujas formas de escolarização não contemplariam as premissas básicas da educação regular, muito menos atendem às compensações necessárias para escolarizar o tipo de estudante que opta ou é deslocado para a escola noturna.

Se pensarmos na condição de jovem e trabalhador, imaginamos que a escola afeta, direta ou indiretamente, tanto as expetativas quanto a qualidade de escolarização desses indivíduos. Corrochano (2013), ao analisar as aspirações de jovens trabalhadores para o acesso ao ensino superior, concluiu que o ingresso na graduação fazia parte do conjunto de projetos destes jovens. Todavia, essas expectativas eram sufocadas pelas necessidades imediatas; ou as esperanças eram a de atingir esse objetivo, porém em um futuro muito distante e dependente de uma ocupação profissional mais favorável. Uma parcela de 
jovens trabalhadores, nos projetos de continuidade dos estudos, enfrenta obstáculos a ponto de frear suas expectativas de conciliação entre trabalho e formação acadêmica, de modo que termina desestimulada na busca pelo ensino superior (CORROCHANO, 2013). Dados do INEP de 2019 indicam que apenas 21,4\% dos jovens entre 18 e 24 anos estão cursando o ensino superior no Brasil (BRASIL, 2020).

Ainda que haja um aparato legal para mediar a relação do estudante-trabalhador com seu vínculo de emprego formal, é sabido que as garantias legais não dão conta de atender às necessidades deste tipo de estudante e também não são suficientes para as demandas geradas pelos estudantes-atletas. A característica do esporte acaba por exigir do atleta exclusividade em certos momentos, o que o difere do trabalhador ordinário, cujo contrato de trabalho, geralmente, acompanha uma rotina esquadrinhada e quase sempre constante. Além disso, ainda existe a ideia de que os estudantes que trabalham têm maior probabilidade de ocupar uma posição de baixo status no mercado de trabalho futuramente, muitas vezes motivada pela demanda gerada pela dupla jornada entre o trabalho e a educação (BRITO, 2009).

Por mais que saibamos que é perigoso assumir o discurso pessimista, uma vez que existem escolas com alunado de perfil socioeconômico desfavorável produzindo resultados além das expectativas estimadas pelas pesquisas em educação, devemos observar que o aparato escolar ainda pode reproduzir desigualdade, oferecendo melhores oportunidades para uns em detrimento de outros (SOARES; ANDRADE, 2006). Além disso, somam-se as características dos adolescentes e jovens que tendem a lidar com as emoções de modo mais intenso e assumem mais riscos nas suas tomadas de decisão (SCHWARTZMAN, 2016).

Nesse contexto, os estudantes-atletas, inseridos no universo de formação profissional dos grandes clubes de futebol, acreditam que as oportunidades no esporte de alto rendimento são mais exequíveis que a formação acadêmica (ROCHA, 2017; CORREIA, 2018). Claro que os desejos, as crenças e a percepção das oportunidades auxiliam a moldar as decisões nesses contextos (ELSTER, 1994; 2009). Com isso, os estudantes-atletas do futebol de alto rendimento administram a carreira esportiva e a escolar apostando mais na primeira que na segunda (SOARES et. al., 2013). Assim, a escolarização é administrada em função da obrigatoriedade e das pressões sociais para conclusão da escola básica.

A rotina diária de um estudante-atleta em formação profissional tem todo o tempo esquadrinhado e limitado por alguma atividade obrigatória. Seja pela escola ou pelo treinamento, os estudantes-atletas têm pouco tempo livre para o lazer e outras atividades sociais (MELO, 2010). Uma vantagem de residir no próprio alojamento do clube é que o tempo de deslocamento para o treino é muito pequeno, sobrando-lhes mais tempo para descansar ou realizar alguma outra atividade de sua vontade, ou necessidade, todavia, isso limita sua interação social com a família e a comunidade de referência (MELO, 2010; SOARES et. al., 2013).

Em contrapartida, quando trabalhamos o tempo de deslocamento para a escola, os dados dos estudantes-atletas mostraram uma realidade diferente para os atletas das categorias sub-15 e sub-17. Enquanto o tempo de deslocamento para os treinamentos é quase inalterável para as duas categorias, quando se trata da escola, o tempo para a categoria com idade maior aumenta consideravelmente. Isso se deve ao fato de as escolas estaduais, onde os estudantes-atletas da sub-17 estavam matriculados, ficarem mais distantes da sede do alojamento do clube, enquanto que a maior parte dos atletas da categoria sub15 estudava no período da tarde, em escola municipal a poucos metros do clube. Percebemos também que na categoria sub-17, todos os atletas matriculados frequentavam a escola no período da noite em função das demandas formativas no futebol. Quanto mais o estudante-atleta se aproxima da categoria profissional, mais ele é requisitado a participar do treinamento e das viagens de sua categoria e da principal, o que torna mais difícil a administração da escolarização no período diurno. Os atletas do ensino noturno apresentavam mais dificuldades de deslocamento na cidade e ainda dependiam, em geral, de transporte público, que nem sempre apresenta regularidade em seus horários (SILVEIRA; COCCO, 2013). Este dado corrobora o debate sobre a diminuição do tempo de permanência na escola e as possíveis formas de adaptação leniente que a escola é submetida ao lidar com as contingências que envolvem a gestão escolar no período da noite.

O futebol é uma modalidade esportiva que exige muito esforço e dedicação dos atletas em formação e é comum observarmos que os atletas iniciam sua carreira nesse esporte muito cedo. Além disso, o cansaço físico declarado por eles, em decorrência da rotina de treinamento e competições, 
possivelmente gera, como relatam, dificuldades de concentração para acompanhar as aulas no dia a dia (BLODGET'T, SCHINKE, 2015; CHRONI, DIAKAKI, PAPAIOANNOU, 2013; METSÄ-TOKILA, 2002; TSHUBE, FELTZ, 2015; SOARES et. al., 2013). Carvalho (2015), em pesquisa com estudantesatletas evadidos do ensino superior, verificou que 35\% afirmaram que o cansaço físico e os deslocamentos foram as causas principais da evasão da instituição de ensino.

\section{CONSIDERAÇÕES FINAIS}

O Tempo de Permanência na Escola (TPE) dos estudantes-atletas de futebol, comparandoo com o tempo de treinamento nesse esporte, demonstra como ocorre a conciliação entre a rotina de treinamento e competições e a permanência na escola. A variável tempo foi utilizada para entender que o tempo destinado é um importante fator para decifrar o quanto as pessoas investem em uma determinada atividade. No caso do futebol e da escola, o estudo sugere que as obrigações das duas formações são concorrentes, e não complementares como seria desejável. De fato, a concorrência entre essas duas agências de formação demonstrou que o futebol demanda mais dedicação do ponto de vista objetivo. A dedicação dos estudantes-atletas apresenta um tempo constante e sem variação em relação ao treinamento e às atividades do esporte. Noutra direção, o tempo médio de permanência na escola, além de mais baixo, apresenta variação entre as categorias e entre os próprios estudantes-atletas.

Considerando-se que: (1) há um contexto de insegurança jurídica para a garantia do direito dos estudantes-atletas ao acesso à e à permanência na escola; (2) as demandas do futebol encaminham o estudante-atleta desta modalidade para o ensino noturno; e (3) a desorganização e o não cumprimento das normativas legais demonstram que o projeto de escolarização para os estudantes do período noturno pode ser secundarizado pela própria instituição de ensino, em função das contingências que a envolvem e pelos próprios atletas, a partir das suas decisões, escolhas e seus desejos, podemos afirmar que o não reconhecimento da condição específica do estudante-atleta como trabalhador ou aprendiz de uma profissão no esporte faz com que os indivíduos envolvidos (atletas, clube, dirigentes e instituições escolares) estabeleçam acordos informais no processo de conciliação da dupla carreira. Acordos estes que nem sempre zelam pelo vínculo e pela dedicação do estudante-atleta à escola.

Devemos entender que a inflexibilidade do clube com seus horários e rotinas e a flexibilidade da escola, principalmente, no ensino noturno, decorre da percepção, dos objetivos e das expectativas que ambas as instituições possuem em relação aos jovens que as frequentam. Com isso, conclui-se que o projeto de escolarização dos estudantes-atletas que frequentam a escola noturna estaria sendo negligenciado, uma vez que as normativas legais não são plenamente atendidas. Destaque-se que a desorganização da estrutura de funcionamento da escola noturna atinge a população de estudantes que frequenta essa modalidade de ensino (Educação de Jovens e Adultos), a qual já é, por sua própria razão de existir, um efeito dos mecanismos que reforçam as desigualdades de oportunidades educacionais. Todavia, chamamos a atenção para o fato de, para além de pertencer à população de estudantes do período noturno, a condição de estudante-atleta traz alguns obstáculos para este grupo com características específicas, de uma modalidade de trabalho ou de aprendizagem profissional que carece de regulamentação no atendimento escolar. Nesse sentido, vislumbra-se que as desigualdades de oportunidades educacionais podem ser potencializadas para o perfil do estudante que busca a carreira esportiva como meio de profissionalização.

\section{REFERÊNCIAS}

BECKER, Howard Saul. Outsiders: estudos de sociologia do desvio. Rio de Janeiro: Zahar, 2008.

BLODGETT, Amy T.; SCHINKE, Robert J. "When you're coming from the reserve you're not supposed to make it": stories of aboriginal athletes pursuing sport and academic careers in "mainstream" cultural contexts. Psychology of Sport and Exercise, v. 21, p. 115-124, 2015. 
BRASIL. Lei de Diretrizes e Bases da Educação Nacional. Lei n 9.394, de 20 de dezembro de 1996. Estabelece as diretrizes e bases da educação nacional. Brasília: 1996. Disponível em: http://www.planalto.gov.br/ccivil_03/leis/19394.htm. Acesso em: 04 ago. 2011.

BRASIL. Lei $\mathbf{n}^{\mathbf{0}} \mathbf{9 . 6 1 5}$, de 24 de março de 1998. Institui normas gerais sobre desporto e dá outras providências. $\quad$ Brasília: $1998 . \quad$ Disponível em: http://www.planalto.gov.br/ccivil_03/leis/L9615consol.htm. Acesso em: 07 out. 2016.

BRASIL. Lei $\mathbf{n}^{\circ} \mathbf{1 2 . 3 9 5}$, de 16 de março de 2011. Altera as Leis $\mathrm{n}^{\circ} \mathrm{s}$ 9.615, de 24 de março de 1998, que institui normas gerais sobre desporto, e 10.891, de 9 de julho de 2004, que institui a Bolsa-Atleta; cria os Programas Atleta Pódio e Cidade Esportiva; revoga a Lei nº 6.354, de 2 de setembro de 1976; e dá outras providências. Brasília, 2011. Disponível em: http://www.planalto.gov.br/ccivil_03/_ato20112014/2011/lei/112395.htm. Acesso em: 07 out. 2016.

BRASIL. Lei $\mathbf{n}^{\mathbf{0}}$ 12.711, de 29 de agosto de 2012. Dispõe sobre o ingresso nas universidades federais e nas instituições federais de ensino técnico de nível médio e dá outras providências. Brasília: 2012. Disponível em: http://www.planalto.gov.br/ccivil_03/_ato2011-2014/2012/lei/112711.htm. Acesso em: 07 out. 2016.

BRASIL. Projeto de Lei $\mathbf{n}^{\mathbf{0}}$ 2.493, de 24 de abril de 2019. Altera a Lei no 9.394, de 20 de dezembro de 1996, que estabelece as diretrizes e bases da educação nacional, e altera a Lei no 12.711, de 29 de agosto de 2012, que dispõe sobre o ingresso nas universidades federais e nas instituições federais de ensino técnico de nível médio e dá outras providências. Brasília: Senado Federal, 2019a. Disponível em: $<$ https://www25.senado.leg.br/web/atividade/materias/-/materia/136475>. Acesso em: 02 abr. 2020.

BRASIL. Projeto de lei $\mathbf{n}^{\circ}$ 4.393, de 13 de agosto de 2019. Que dispõe sobre a assistência, em regime de exercícios domiciliares ou à distância, para estudantes da Educação Básica que participem periodicamente de competições desportivas e paradesportivas ou exerçam atividades artísticas itinerantes. Brasília: Senado Federal, 2019b. Disponível em: https://www25.senado.leg.br/web/atividade/materias//materia/138079. Acesso em: 02 abr. 2020.

BRASIL. Instituto Nacional de Estudos e Pesquisas Educacionais Anísio Teixeira (Inep). Censo da Educação Superior 2019: notas estatísticas. Brasília: 2020. Disponível em: https://download.inep.gov.br/educacao_superior/censo_superior/documentos/2020/Notas_Estatisti cas_Censo_da_Educacao_Superior_2019.pdf. Acesso em: 02 abr. 2020.

BRITO, Murillo Marschner de. Discutindo o trabalho de crianças e adolescentes no Brasil - curso da vida, sentidos da ação econômica e transmissão intergeracional. In: NEVES, J. A.; FERNANDES, D. C.; HELAL, D. H. (Orgs.). Educação, Trabalho e Desigualdade Social. Belo Horizonte: Argumentum, 2009, 240p.

CARDOSO, Adalberto. Juventude, trabalho e desenvolvimento: elementos para uma agenda de investigação. CADERNO CRH, Salvador, v. 26, n. 68, p. 293-314, Maio/Ago. 2013. Disponível em: <http://www.scielo.br/pdf/ccrh/v26n68/a06v26n68.pdf >. Acesso em: 10 jun. 2014.

CARVALHO, Ricardo Antonio Torrado de. Atleta não estuda? Investigando a evasão escolar de alunos-atletas na Educação Superior. Dissertação (Mestrado em Educação) - Programa de Pós-graduação em Educação da Universidade da Cidade de São Paulo - UNICID, São Paulo, 2015.

CHRONI, Stiliani Ani.; DIAKAKI, Eleni.; PAPAIOANNOU, Athanasios. Athletes' careers in Greece: Towards a culturally infused future. In: STAMBULOVA, N. B.; RYBA, T. V. (Eds.). Athletes' careers across cultures. Ebook ed. New York: Taylor \& Francis Group, 2013, 288p. 
CORREIA, Carlus Augustus Jourand. Entre a profissionalização e a escolarização: projetos e campo de possibilidades em jovens atletas do Colégio Vasco da Gama. 2014. Dissertação (Mestrado em Educação) - Programa de Pós-graduação em Educação, Universidade Federal do Rio de Janeiro, Rio de Janeiro, 2014. Disponível em: <http://www.educacao.ufrj.br/dcarlusaugustus.pdf > . Acesso em: 07 out. 2016.

CORREIA, Carlus Augustus Jourand. Projetos familiares na formação de atletas do futebol: Apostas na profissionalização e na escolarização. 2018. Tese (Doutorado em Educação) - Dilemas da dupla carreira 73 CSOnline - Revista Eletrônica de Ciências Sociais, Juiz de Fora, n. 31 (2020) Programa de Pós-graduação em Educação, Universidade Federal do Rio de Janeiro, Rio de Janeiro, 2018.

CORROCHANO, Maria Carla. Jovens trabalhadores: expectativas de acesso ao ensino superior. Avaliação (Campinas), Sorocaba, v. 18, n. 1, p. 23-44, mar. 2013. Disponível em: http://dx.doi.org/10.1590/S1414-40772013000100003. Acesso em: 07 out. 2016.

COSTA, Ana Luiza Jesus da. As escolas noturnas do município da Corte: estado imperial, sociedade civil e educação do povo (1870-1889). Educ. Soc., Campinas, v. 32, n. 114, p. 53-68, mar. 2011. Disponível em: https://www.scielo.br/scielo.php?pid=S010173302011000100004\&script=sci_abstract\&tlng=pt\#: :text=Luiza\%20Jesus\%20da.,As $\% 20$ escolas $\% 20$ noturnas $\% 20 \mathrm{do} \% 20$ munic $\%$ C3 $\%$ ADpio $\% 20 \mathrm{da} \% 20$ Corte $\% 3 \mathrm{~A} \% 20$ estado $\% 20 \mathrm{imper}$ ial $\% 2 \mathrm{C} \% 20$ sociedade,Educ.\&text $=$ Este $\% 20$ trabalho $\% 20$ exp $\% \mathrm{C} 3 \% \mathrm{~B} 5 \mathrm{e} \% 20$ parte $\% 20 \mathrm{dos}$,experi $\% \mathrm{C} 3 \%$ AAncia\%20de\%20educa \%C3\%A7\%C3\%A3o\%20do\%20povo. Acesso em: 30 maio 2018.

COSTA, Felipe Rodrigues da. A escola, o esporte e a concorrência entre estes mercados para jovens atletas mulheres no futsal de Santa Catarina. 2012. Tese (Doutorado em Educação Física) - Programa de Pós-graduação em Educação Física, Universidade Gama Filho, Rio de Janeiro, 2012.

COSTA E SILVA, André Luiz da. Esporte e escolarização: projetos, biografias e programa governamental. Dissertação (Mestrado em Educação Física) - Programa de Pós-graduação em Educação Física, Centro de Educação Física e Desportos, Universidade Federal do Espírito Santo, Vitória-ES, 2016.

ELSTER, Jon. Peças e engrenagens das ciências sociais. Trad. /Jon Elster; tradução de Antônio Trânsito; revisão técnica de Plínio A. S. Dentzien. Rio de Janeiro: Relume-Dumará, 1994.

ELSTER, Jon. Ulisses Liberto: estudos sobre racionalidade, pré-compromisso e restrições. Trad. Cláudia Sant'Ana Martins. São Paulo: Editora UNESP, 2009.

EMMERICK, Daniela Calache. Escolarização de jovens atletas: a dupla carreira de atletas da elite do judô no Brasil. Dissertação (Mestrado em Educação) - Programa de Pós-graduação em Educação, Universidade Federal do Rio de Janeiro, Rio de Janeiro, 2019. Disponível em: < https://ppge.educacao.ufrj.br/dissertacoes2019/Dissertacao\%20Daniela\%20Calache\%20Emmerick.pd f>. Acesso em: 20 dez. 2020.

EUROPEAN COMMISSION. White Paper on Sport. 2007. Disponível em: <http://eur-lex. europa.eu/legal-content/EN/TXT/PDF/?uri=CELEX:52007DC0391\&from=em>. Acesso em: 17 nov. 2016.

EUROPEAN COMMISSION. Guidelines on dual careers of athletes - Recommended policy actions in support of dual careers in high-performance sport. 2012. Disponível em: < http://ec.europa.eu/assets/eac/sport/library/documents/dual-career-guidelines-final_en.pdf >. Acesso em: 17 nov. 2016.

GUIDOTTI, Flavia.; CORTIS, Cristina; CAPRANICA, Laura. Dual Career of european student athletes: a systematic literature review. Kinesiologia Slovenica, v. 21, n. 3, p. 5-20, 2015. 
KRAWCZYK, Nora. Reflexão sobre alguns desafios do ensino médio no Brasil hoje. Cad. Pesqui., São Paulo , v. 41, n. 144, p. 752-769, Dec. 2011 . Disponível em: $<$ http://www.scielo.br/scielo.php?script=sci_arttext\&pid=S010015742011000300006\&lng=en\&nrm=iso>. Acesso em: 08 Jan. 2021. https://doi.org/10.1590/S010015742011000300006.

LEAO, Geraldo. O que os jovens podem esperar da reforma do ensino médio brasileiro?. Educ. rev., Belo Horizonte , v. 34, e177494, 2018. Disponível em: $<$ http://www.scielo.br/scielo.php?script=sci_arttext\&pid=S010246982018000100126\&lng=en\&nrm=iso>. Acesso em: 08 Jan. 2021. Epub Mar 05, 2018. https://doi.org/10.1590/0102-4698177494.

LÓPEZ DE SUBIJANA, Cristina.; EQUIZA VAQUERO, Xavier. La retirada en natación: La vida fuera del agua. Revista Española de Educación Física y Deportes, n. 421, p. 101-121, 2018.

MATEU, Pau; VILANOVA, Anna; INGLÉS, Eduard. Análisis de las características organizativas de los programas de apoyo a estudiantes-deportistas de élite en el sistema universitario de Cataluña. Movimento, Porto Alegre, v. 24, n. 4, p. 1205-1218, out./dez. 2018.

MELO, Leonardo. Bernardes Silva de. Formação e escolarização de jogadores de futebol do Estado do Rio de Janeiro. 2010. Dissertação (Mestrado em Educação Física) - Programa de Pós-Graduação em Educação Física, Universidade Gama Filho, Rio de Janeiro, 2010.

MELO, Leonardo Bernardes Silva de; SOARES, Antonio Jorge Gonçalves.; ROCHA, Hugo Paula Almeida da. Perfil educacional de atletas em formação no futebol no Estado do Rio de Janeiro. Rev. bras. educ. fís. esporte, São Paulo, v. 28, n. 4, p. 617-628, dez. 2014. Disponível em $<$ http:/ /www.scielo.br/scielo.php?script=sci_arttext\&pid=S180755092014000400617\&lng=pt\&nrm $=\mathrm{i}$ so >. Acesso em: 07 out. 2016.

MELO, Leonardo Bernanrdes Silva de., et. al. Jornada escolar versus tempo de treinamento: a profissionalização no futebol e a formação na escola básica. Rev. Bras. Ciênc. Esporte. 2016. Disponível em: <http://dx.doi.org/10.1016/j.rbce.2015.11.003>. Acesso em: 07 out. 2016.

METSÄ-TOKILA, Timo. Combining competitive sports and education: how top-level sport became part of the school system in the Soviet Union, Sweden and Finland. European Physical Education Review, v. 8, n. 3, p. 196-206, 2002.

NERI, Marcelo Côrtes. Tempo de Permanência na Escola. Rio de Janeiro: FVG/IBRE, CPS, 2009. Disponível em: <http://www.fgv.br/cps/tpe/>. Acesso em: 10 jun. 2011.

PATO, Antonio Sánchez.; ISIDORI, Emanuele.; CALDERÓN, Antonio. Developing an innovative European Sport Tutorship for the dual career of athletes. Murcia: UCAM Catholic University of Murcia, 2017.

RIBEIRO, Carlos Antonio Costa. Desigualdade de oportunidades no Brasil. Belo Horizonte: Argvmentvm, 2009.

RIBEIRO, Carlos Antonio Costa. Desigualdade de Oportunidades e Resultados Educacionais no Brasil. Revista de Ciências Sociais, Rio de Janeiro, v. 54, n. 1, p. 41-87, 2011. Disponível em: <http://www.scielo.br/pdf/dados/v54n1/02.pdf >. Acesso em: 15 abr. 2014.

ROCHA, Hugo Paula Almeida da. A escola dos jóqueis: a escolha da carreira do aluno atleta. 2013. Dissertação (Mestrado em Educação) - Programa de Pós-graduação em Educação, Universidade Federal do Rio de Janeiro, Rio de Janeiro, 2013. Disponível em: <http://labecufrj.com/dissertacoes/disserhugopaula.pdf>. Acesso em: 04 jul. 2013. 
ROCHA, Hugo Paula Almeida da. O futebol como carreira, a escola como opção: o dilema do jovem atleta em formação. 2017. Tese (Doutorado em Educação) - Programa de Pós-Graduação em Educação, Universidade Federal do Rio de Janeiro, Rio de Janeiro, 2017. Disponível em: <http://www.educacao.ufrj.br/ppge/teses2017/tHugoAlmeida.pdf>. Acesso em: 30 maio 2018.

RODRÍGUEZ MARTÍNEZ, Maria.; CRUZ, Jaume.; TORREGROSSA, Miquel. Intervention program with coaches and parents: effects of the coach's behavior and the team's motivational climate. Revista de Psicologia del Deporte, v. 26, n. 4, p. 181-187, 2017. Disponível em: <https://www.rpdonline.com/article/view/v26-n4-rodriguez-martinez-cruz-etal>. Acesso em: 20 dez. 2020.

SCHWARTZMAN, Simon. O viés acadêmico na educação brasileira. Pensamiento Educativo, Revista de Investigación Educacional Latinoamericana (PEL), Santiago do Chile, v. 48, n. 1, 2011. Disponível em: <http://www.schwartzman.org.br/simon/agenda9.pdf>. Acesso em: 01 dez. 2011.

SCHWARTZMAN, Simon. Educação média profissional no Brasil: situação e caminhos. São Paulo: Fundação Santillana, 2016.

SILVEIRA, Marcio Rogerio.; COCCO, Rodrigo Giraldi. Transporte público, mobilidade e planejamento urbano: contradições essenciais. Estud. Av., São Paulo, v. 27, n. 79, p. 41-53, 2013. Disponível em: $<$ http:/ /www.scielo.br/scielo.php?script=sci_arttext\&pid=S0103-

40142013000300004\&lng=en\&nrm=iso >. Acesso em: 03 Jan. 2021. https://doi.org/10.1590/S010340142013000300004.

SOARES, Antonio Jorge Gonçalves.; ROCHA, Hugo Paula Almeida da; COSTA, Felipe Rodrigues. A Escola dos Jóqueis: a aposta de carreira do aluno atleta. In: XV Congresso Brasileiro de Sociologia. 2011, Curitiba-PR. Disponível em: <http://www.sistemasmart.com.br/sbs2011/arquivos/30_6_2011_15_53_43.pdf> Acesso em: 04 ago. 2011.

SOARES, José Francisco.; ANDRADE, Renato Júdice de. Nível socioeconômico, qualidade e eqüidade das escolas de Belo Horizonte. Ensaio: Aval. Pol. Públ. Educ., Rio de Janeiro, v. 14, n. 50, p. 107-125, mar. 2006. Disponível em: <http://www.scielo.br/scielo.php?script=sci_arttext\&pid=S010440362006000100008\&lng=en\&nrm=iso >. Acesso em: 07 out. 2016.

SOARES, Antonio Jorge Gonçalves.; MELO, Leonardo Bernardes Silva de.; BARTHOLO, Tiago Lisboa.; VELARDE, Luis Guillermo Coca.; RIBEIRO, Carlos Henrique Vasconcelos.; SANTOS, Tony Meireles dos. Time for football and school: an analysis of young brazilian players from Rio de Janeiro. Estúdios Sociológicos, v. 31, p. 1-14, 2013.

SOUZA, Camilo Araújo Máximo de.; et al. Difícil reconversão: futebol, projeto e destino em meninos brasileiros. Horiz. Antropol., Porto Alegre, v. 14, n. 30, dez. 2008. Disponível em: $<$ http:/ / www.scielo.br/scielo.php?script=sci_arttext\&pid=S0104-

71832008000200004\&lng=en\&nrm=iso >. Acesso em: 20 dez. 2010.

STAMBULOVA, Natalia. B.; WYLLEMAN, Paul. Psychology of athletes' dual careers: A state-of-theart critical review of the European discourse. Psychology of Sport \& Exercise, v. 42, p. 74-88, 2019.

TSHUBE, Tshube.; FELTZ, Debora L. The relationship between dual-career and post-sport career transition among elite athletes in South Africa, Botswana, Namibia and Zimbabwe. Psychology of Sport and Exercise, v. 21, p. 109-114, 2015. 